\title{
Reduced upper airway nitric oxide in cystic fibrosis
}

\author{
Ian M Balfour-Lynn, Aidan Laverty, Robert Dinwiddie
}

\begin{abstract}
Nitric oxide (NO) produced within the respiratory tract is detectable in exhaled and nasal air. Its synthesis may be induced by inflammatory cytokines and reduced by glucocorticoids. Increased concentrations have been found in asthma and bronchiectasis. In this study, NO concentrations were determined in 63 children with cystic fibrosis, of whom 13 were on inhaled steroids (mean age 13.3 years) and 50 were not (mean age 12.3 years); 57 normal children (mean age 12.2 years) were also studied. NO was measured by chemiluminescence analyser, exhaled NO following a relaxed vital capacity manoeuvre, and nasal NO with the breath held following a full inspiration. Mean concentration of exhaled NO in cystic fibrosis patients (no steroids) was 4.7 parts per billion (ppb) (95\% confidence interval (CI) 4.0 to 5.3 ); this did not differ from values in normal children (mean $4.8 \mathrm{ppb}, 95 \%$ CI 3.8 to 5.8 ) or in cystic fibrosis patients on inhaled steroids (mean $3.6 \mathrm{ppb}, 95 \%$ CI 2.5 to 4.8). Nasal concentrations were significantly lower in cystic fibrosis patients, with or without inhaled steroids, than in normal children (cystic fibrosis, no inhaled steroids: 460 ppb, 95\% CI 399 to 520; cystic fibrosis, inhaled steroids: $522 \mathrm{ppb}, 95 \%$ CI 313 to $730, v$ normal children: 1024 ppb, 95\% CI 896 to $1152, p<0.0001)$. Considering the inflammatory nature of cystic fibrosis, it is surprising exhaled NO levels were not increased, but this may have been due to alteration in NO diffusion through thick mucus. The low nasal NO concentrations, which are probably the result of impaired flow from the paranasal sinuses, may contribute to the recurrent respiratory infections typical of cystic fibrosis.

(Arch Dis Child 1996;75:319-322)
\end{abstract}

Keywords: cystic fibrosis, nitric oxide, lung inflammation, inhaled glucocorticoids.

Respiratory Unit, Great Ormond Street Hospital for Children NHS Trust, Great Ormond Street, London WC1N 3JH I M Balfour-Lynn

A Laverty

R Dinwiddie

Correspondence to: Dr Balfour-Lynn.

Accepted 4 July 1996 most methods of monitoring lung inflammation in cystic fibrosis are unsatisfactory, although inflammatory markers such as cy- tokines or proteases can be measured in bronchoalveolar lavage (BAL) fluid or sputum. ${ }^{4} \mathrm{BAL}$ is invasive and has methodological problems, including the effects of dilution and variability, ${ }^{5}$ while not all children with cystic fibrosis produce sputum. A potential noninvasive marker of lung inflammation might be exhaled nitric oxide (NO), and this approach has been suggested for monitoring asthma therapy. ${ }^{6}$

$\mathrm{NO}$ is a simple gas involved in the regulation of numerous pulmonary functions, ${ }^{7}$ including upregulation of ciliary motility. ${ }^{8}$ In addition, NO plays a part in the host inflammatory response, particularly non-specific defence mechanisms, ${ }^{10}$ with both antibacterial ${ }^{11}$ and antiviral activity. ${ }^{12}{ }^{13}$ It is synthesised from L-arginine by an enzyme nitric oxide synthase (NOS) which has several isoforms. The inducible form (iNOS) is expressed after exposure to certain proinflammatory cytokines and endotoxin but is inhibited by glucocorticoids. ${ }^{7}$ 9 Within the respiratory tract, endogenous $\mathrm{NO}$ is produced by several cells, including alveolar macrophages, airway epithelial cells, neutrophils, and mast cells. ${ }^{14}$ This NO can be directly measured in exhaled alveolar air and in air sampled from the upper airways. ${ }^{15}$

Nitric oxide is also associated with several diseases of the lungs. Work in adults has shown raised concentrations of exhaled $\mathrm{NO}$ in patients with asthma ${ }^{6}{ }^{16}$ and bronchiectasis, ${ }^{17}$ with asthmatics also having raised nasal NO levels. ${ }^{18}$ However, when treated with inhaled steroids, these patients have normal amounts of exhaled NO. $^{6}{ }^{17}{ }_{19}$ Raised NO concentrations may reflect increased expression of iNOS as part of the chronic cytokine mediated inflammation that characterises these conditions. ${ }^{17}$ NOS activity in lung tissue has been shown to be increased in inflammatory lung diseases, including asthma and cystic fibrosis. ${ }^{20}{ }^{21}$ It would be expected that children with cystic fibrosis would have increased production of NO in the respiratory tract since cytokines known to induce iNOS (for example, tumour necrosis factor $\alpha$, interleukin-1 $\beta$ ) have been shown to be produced in increased amounts in the cystic fibrosis lung. ${ }^{22}{ }^{23}$ The aim of this study was to measure NO in exhaled and nasal air in cystic fibrosis children, including some taking inhaled steroids, and compare these with values found in normal children.

\section{Methods}

SUBJECTS

Patients studied were children who all had a proven diagnosis of cystic fibrosis previously confirmed by a sweat test. Exclusion criteria 
were current oral or inhaled corticosteroid therapy, upper respiratory tract infection, concomitant diagnosis of bronchial asthma, or age under 6 years. There were 50 patients in this group (27 girls, 23 boys) aged 7 to 17 years (mean age 12.3 years). The $\mathrm{FEV}_{1}$ (forced expiratory volume in one second) of the patients ranged from $24 \%$ to $104 \%$ (mean $64 \%$ ) of that predicted for sex and height. ${ }^{24} \mathrm{~A}$ second group of cystic fibrosis patients who had taken inhaled steroids for at least six weeks was studied. None of these had a concomitant clinical diagnosis of asthma and they were taking doses ranging from 200 to $1000 \mu \mathrm{g} /$ day. There were 13 children in this group (nine girls, four boys) aged 9 to 7 years (mean age 13.3 years) with $\mathrm{FEV}_{1}$ ranging from $25 \%$ to $88 \%$ (mean $65 \%$ ) of predicted value. Normal children attending local schools were also studied. Their exclusion criteria were the same as for the patients. There were 57 normal children ( 30 girls, 27 boys) in this group, aged 6 to 17 years (mean 12.2 years). The study was approved by the hospital ethics committee and consent was obtained from both the parents and the children.

\section{PROCEDURES}

Nitric oxide measurement

NO was measured by a chemiluminescence analyser LR2000 Series (Logan Research, Rochester, UK). This gave continuous on-line recordings with a limit of resolution of about 1 part per billion (ppb). End tidal carbon dioxide $\left(\mathrm{CO}_{2}\right)$ was measured simultaneously by infra red absorption. When measuring exhaled air, the trace was observed until the end tidal $\mathrm{CO}_{2}$ reached a plateau; from this it was assumed the air sampled at that moment was 'alveolar' and NO concentrations were recorded. During the nasal measurements, nasal $\mathrm{CO}_{2}$ was also monitored to ensure exhalation was not taking place. Nasal NO concentrations were recorded when the values reached a plateau. Ambient air NO was also recorded at the same time.

\section{Exhaled air sampling}

After maximum inspiration, subjects exhaled slowly for as long as possible (slow vital capacity manoeuvre) into a wide bore tube (internal diameter $10 \mathrm{~mm}$ ). This offered little resistance to air flow, thus measuring 'free flow' exhaled NO. A fine bore Teflon tube, connected directly to the analyser, continuously sampled the exhaled air adjacent to a mouthpiece at $0.25 \mathrm{l} / \mathrm{min}$. The test was repeated three times with a 2 min rest period, and the average value was calculated.

\section{Nasal air sampling}

Subjects placed a plastic nosepiece just inside one nostril; this was connected via a fine bore Teflon tube directly into the NO analyser. They took a deep breath and held it as long as possible, ensuring they did not exhale through the nose. Air was sampled continuously from the nose at $0.25 \mathrm{1} / \mathrm{min}$. This test was also repeated three times with a 2 min rest period, and the average value was calculated.
Table 1 Exhaled free flow nitric oxide (parts per billion) in patients with cystic fibrosis and normal children

\begin{tabular}{lllll}
\hline & \multicolumn{4}{c}{ Exhaled free flow nitric oxide (ppb) } \\
\cline { 2 - 5 } & Number & Mean & $95 \%$ CI & Range \\
\hline Cystic fibrosis (no & 50 & 4.7 & 4.0 to & 1.1 to \\
steroids) & & & 5.3 & 11.3 \\
Cystic fibrosis & 13 & 3.6 & 2.5 to & 1.0 to 6.7 \\
(steroids) & & & 4.8 & \\
Normal children & 57 & 4.8 & 3.8 to & 1.1 to \\
& & & 5.8 & 23.0 \\
\end{tabular}

$\mathrm{CI}=$ confidence interval

\section{STATISTICS}

Statistical analysis was performed using Minitab software (Minitab Inc, State College, PA, USA). Unpaired $t$ tests and one way analysis of variance were used to compare the different groups. Values of $p<0.05$ were considered significant.

\section{Results}

SAMPLING TIMES AND VARIABILITY

Exhalation times for cystic fibrosis patients and normal children were similar, with a mean of 24 (range 12 to 43 ) seconds. During the nasal sampling, the cystic fibrosis children held their breath for a significantly shorter time than the normal children, with a mean of 30 (range 17 to 51 ) seconds $v 37$ (range 17 to 65 ) seconds. The mean difference was 7 (95\% confidence interval (CI) 5 to 9) seconds, $\mathrm{p}<0.001$. However, cystic fibrosis children still managed to hold their breath long enough to obtain satisfactory results on the analyser. Ambient air NO ranged from 2 to $22 \mathrm{ppb}$ on different days.

Intrasubject variability was ascertained by calculating the mean coefficient of variation for the repeat tests performed by each subject. For exhaled NO this was $24.8 \%$ for the cystic fibrosis patients and $28.4 \%$ for the normal subjects, and for nasal NO it was $6.8 \%$ for cystic fibrosis patients and $4.1 \%$ for normal subjects.

\section{EXHALED FREE FLOW NITRIC OXIDE}

Exhaled NO was detected in all subjects but there was no difference in levels between cystic fibrosis and normal children (table 1, fig 1). Among the cystic fibrosis children, use of inhaled steroids did not affect exhaled NO. There was no significant difference in exhaled NO concentrations between those colonised with Pseudomonas aeruginosa $(\mathrm{n}=26)$ and those not colonised $(n=24)$. However, exhaled NO was lower in those colonised with Staphylococcus aureus $(\mathrm{n}=31)$ compared to those free of the organism $(n=19)$, with means of 4.0 ppb (95\% CI 3.4 to 4.6$)$ v $5.8 \mathrm{ppb}(95 \%$ CI 4.4 to 7.2$), p<0.02$. Exhaled NO was correlated with neither $\mathrm{FEV}_{1}(r=0.16)$ nor FVC $(r=0.33)$ in the patients.

\section{NASAL NITRIC OXIDE}

Nasal NO concentrations were much higher than that found in exhaled air; however, there was no correlation between the two $(r=0.06)$. Children with cystic fibrosis had significantly lower concentrations of nasal NO than the normal subjects (table 2, fig 2), with $\mathrm{p}<0.0001$. 


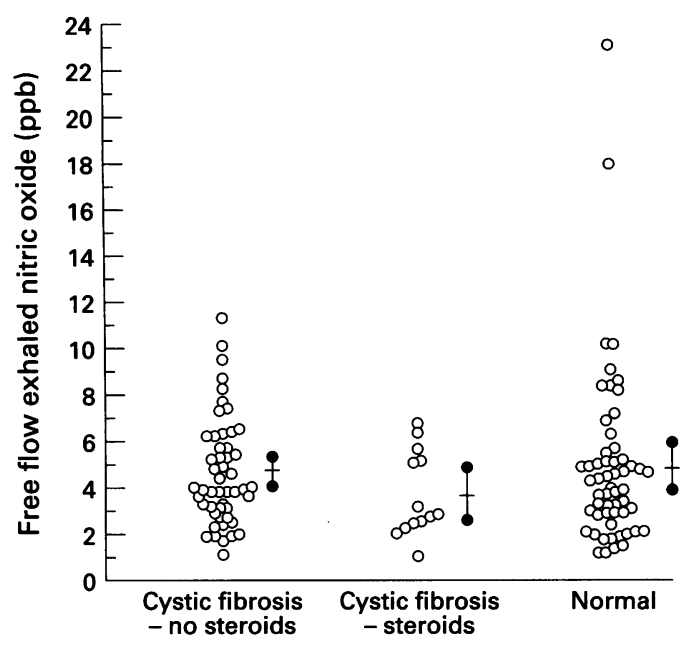

Figure 1 Exhaled free flow nitric oxide (parts per billion) in patients with cystic fibrosis, cystic fibrosis treated with inhaled steroids, and normal children. Also shown are means (bar) with $95 \%$ confidence intervals (solid dots).

Use of inhaled steroids did not affect nasal NO concentrations among the cystic fibrosis children. There was no significant difference in nasal NO values between cystic fibrosis children with nasal polyps $(n=12)$ and those without $(n=21)$. Finally, among the cystic fibrosis children, there was no difference in nasal NO between those colonised with Staphylococcus aureus $(\mathrm{n}=22)$ and those not colonised $(n=11)$; however, nasal NO was significantly lower in those colonised with Pseudomonas aeruginosa $(\mathrm{n}=17)$ compared to those free of the organism $(n=16)$, with means of $378 \mathrm{ppb}$ (95\% CI 306 to 451$)$ v $552 \mathrm{ppb}(95 \%$ CI 467 to 638), $\mathrm{p}<0.003$.

\section{Discussion}

Contrary to expectation, we detected normal concentrations of exhaled NO and low concentrations of nasal NO in children with cystic fibrosis. Furthermore, treatment with inhaled steroids did not affect NO levels. The concentrations of exhaled $\mathrm{NO}$ in normal children were somewhat lower than that measured in normal adults using a similar technique of chemiluminescence. ${ }^{617}$ Although possible, it is unlikely that this is due to an age effect, and there was no correlation of age with NO concentrations in our normal children. It is more likely that our lower values were due to methodological differences which affected resistance to flow when exhaling into the chemiluminescence analyser. We used a low resistance system, and found in preliminary experiments that exhaling through a finer tube, particularly if exhalation becomes strained, produced noticeably higher NO levels. For this reason, we have called our technique 'free flow' exhaled NO. Our levels of exhaled NO are in fact in agreement with measurements made in adults using the technique of gas chromatography-mass spectrometry. ${ }^{25}$

Considering the inflammatory nature of cystic fibrosis lung disease, it was surprising we did not find high levels of exhaled NO. However iNOS activity may still be upregulated in cystic fibrosis, ${ }^{21}$ and perhaps the NO produced in the lungs cannot diffuse freely into the alveolar spaces through the thick mucus.
Table 2 Nasal nitric oxide (parts per billion) in patients with cystic fibrosis and normal children

\begin{tabular}{lllll}
\hline & \multicolumn{3}{l}{ Nasal nitric oxide (ppb) } \\
\cline { 2 - 5 } & Number & Mean & $95 \%$ CI & Range \\
\hline $\begin{array}{c}\text { Cystic fibrosis (no } \\
\text { steroids) }\end{array}$ & 33 & 460 & 399 to & 114 to \\
$\begin{array}{c}\text { Cystic fibrosis } \\
\text { (steroids) }\end{array}$ & 13 & 522 & 313 to & 865 \\
$\begin{array}{c}\text { Normal children } \\
\text { Normal to }\end{array}$ & 54 & 1024 & 896 to & 1274 \\
& & & 1152 & 2502 \\
\end{tabular}

$\mathrm{CI}=$ confidence interval

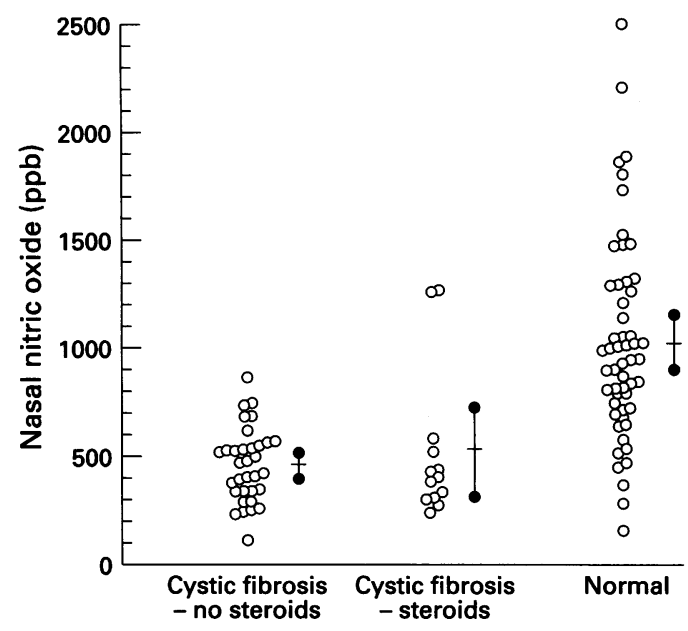

Figure 2 Nasal nitric oxide levels (parts per billion) in patients with cystic fibrosis, cystic fibrosis treated with inhaled steroids, and normal children. Also shown are means (bar) with 95\% confidence intervals (solid dots).

Against this explanation is the fact that high concentrations of NO have been found in bronchiectasis, ${ }^{17}$ a condition which is also associated with thick mucus in the lungs. Another possible explanation is that NO is degraded within the mucus, which could result in lower levels of NO diffusing into the lumen of the airway. NO is known to react with a number of substances produced by inflammatory cells, for example neutrophil derived superoxides react rapidly with NO to produce the toxic oxidant peroxynitrite. Significant concentrations of NO degradation products such as nitrates and nitrites have been measured in cystic fibrosis sputum. ${ }^{26}$ In addition, one of the major pathogens in cystic fibrosis, Pseudomonas aeruginosa, produces a pigment, pyocyanin, which can be detected in lung secretions; concentrations of pyocyanin far lower than that found in the lungs have been shown to inactivate $\mathrm{NO}^{27}$ However, we found that NO concentrations did not correlate with the presence of Pseudomonas aeruginosa in the airways. The lack of influence on NO concentrations from taking inhaled glucocorticoids does not necessarily imply that steroids do not have an antiinflammatory effect in cystic fibrosis lung disease. It does, however, confirm that, unlike in asthma, ${ }^{6}{ }^{19}$ NO concentrations are not a useful method for monitoring lung inflammation in cystic fibrosis.

Nasal NO concentrations are much higher than that found in exhaled air derived from the lungs, and the main source of production is thought to be from the epithelial lining of the paranasal sinuses. ${ }^{28}$ The NO diffuses down a 
concentration gradient (mean NO concentration in maxillary sinuses is 9100 (SD 3800) $\mathrm{ppb}$ ) through the sinus ostia into the nasal cavity. ${ }^{28}$ This may explain the reduced concentrations found in the nose in cystic fibrosis. Almost all patients with cystic fibrosis develop sinus disease, and the frontal sinuses rarely develop. ${ }^{29}$ In addition, the thickened mucus in cystic fibrosis leads to mechanical obstruction of the sinus ostia which is worsened by mucosal oedema and inflammation. ${ }^{29}$ This will impede the flow of NO into the nasal cavity and may also explain the very low nasal NO levels found in Kartagener's syndrome, in which sinusitis (as well as bronchiectasis and situs inversus) is a regular feature. ${ }^{30}$ Another feature common to cystic fibrosis and Kartagener's syndrome is impaired mucociliary function; it is not clear how this might alter NO production, although it may affect diffusion of NO into the airway lumen. Finally, it is possible that initial production of $\mathrm{NO}$ in the sinuses may also be reduced in cystic fibrosis; to prove this, NOS activity in sinus epithelium would need to be studied. Low concentrations of NO in the upper airways of cystic fibrosis patients is an important finding due to the antibacterial nature of NO. In particular, in vitro work has shown NO to be bacteriostatic to Staphylococcus aureus, the primary respiratory pathogen of cystic fibrosis, at concentrations normally found in the upper airways. ${ }^{11}$ However, we did not find any relation between nasal NO levels and the presence of Staphylococcus aureus in the airways.

In conclusion, we did not find raised concentrations of free flow exhaled $\mathrm{NO}$ in cystic fibrosis and we cannot recommend this method for monitoring lung inflammation in this condition. We did, however, find reduced concentrations of nasal NO, which may contribute to the recurrent bacterial respiratory infections suffered by children with cystic fibrosis.

We would like to thank all the children for taking part in this study and the Elizabeth Garrett Anderson School, St George the Martyr Primary School, and Central Foundation Boys School for their cooperation. We would also like to thank D Sergei Kharitonov for initial advice. Finally, IBL received financial support from Glaxo Wellcome UK Ltd.

1 Konstan MW, Berger M. Infection and inflammation of the lung in cystic fibrosis. In: Davis PB, ed. Cystic fibrosis. New York: Marcel Dekker, 1993.

2 Eigen H, Rosenstein BJ, FitzSimmons S, Schidlow DV, Cystic Fibrosis Foundation Prednisone Trial Group. A multicenter study of alternate-day prednisone therat multicenter study of alternate-day prednisone therapy

3 Konstan MW, Byard PJ, Hoppel CL, Davis PB. Effect of high-dose ibuprofen in patients with cystic fibrosis. $N$ Engl high-dose ibuprofen in patie
$\mathcal{f}$ Med $1995 ; 332: 848-54$.
4 Balfour-Lynn IM, Dinwiddie R. Role of corticosteroids in cystic fibrosis lung disease. $\mathcal{F} R$ Soc Med 1996;89(supp 27):8-13.

5 Ramsay BW, Boat TF. Outcome measures for clinical trials in cystic fibrosis. Summary of a Cystic Fibrosis Foundation Consensus Conference. 7 Pediatr 1994;124:177-92.

6 Kharitonov SA, Yates D, Robbins RA, Logan-Sinclair RB, Shinebourne EA, Barnes PJ. Increased nitric oxide in exhaled air of asthmatic patients. Lancet 1994;343:133-5.

7 Barnes PJ, Belvisi MG. Nitric oxide and lung disease. ThoBarnes PJ, Belvisi MG.
$\operatorname{rax}$ 1993;48:1034-43.

8 Jain B, Rubinstein I, Robbins RA, Leise KL, Sisson JH. Modulation of airway epithelial cell ciliary beat frequency by nitric oxide. Biochem Biophys Res Comm 1993;191:83-8.

9 Moncada S, Palmer RMJ, Higgs EA. Nitric oxide: physiology, pathophysiology, and pharmacology. Pharm Rev 1991;43:109-42.

10 Liew FY, Cox FEG, Nonspecific defence mechanism: the role of nitric oxide. Immunol Today 1991;12:A17-21.

11 Mancinelli RL, McKay CP. Effects of nitric oxide and nitrogen dioxide on bacterial growth. Appl Env Micro 1983;46: 198-202.

12 Croen KD. Evidence for an antiviral effect of nitric oxide. Inhibition of herpes simplex virus type I replication. 7 Clin Invest 1993;91:2446-52.

13 Karupiah G, Xie Q-W, Buller RML, Nathan C, Duarte C, MacMicking JD. Inhibition of viral replication by interferon- $\gamma$-induced nitric oxide synthase. Science 1993; 261:1445-48.

14 Gaston B, Drazen JM, Loscalzo J, Stamler JS. The biology of nitrogen oxides in the airways. Am $\mathcal{F}$ Resp Crit Care Med 1994;149:538-51.

15 Gustafsson LE, Leone AM, Persson MG, Wiklund NP, Moncada S. Endogenous nitric oxide is present in the exhaled air of rabbits, guinea-pigs and humans. Biochem Biophys Res Commun 1991;181:852-7.

16 Alving $\mathrm{K}$, Weitzberg $\mathrm{E}$, Lundberg JM. Increased amounts of nitric oxide in exhaled air of asthmatics. Eur Resp $\mathcal{F}$ 1993;6: nitric oxide

17 Kharitonov SA, Wells AU, O'Connor BJ, et al. Elevated levels of exhaled nitric oxide in bronchiectasis. Am $\widetilde{\jmath}$ Resp Crit els of exhaled nitric oxide in b

18 Kharitonov SA, Rajakulasingamm KR, O'Connor BJ, Durham SR, Barnes PJ. Nasal nitric oxide is increased in patients with asthma and allergic rhinitis and may be modulated by nasal glucocorticosteroids [abstr]. Thorax 1995;50(suppl 2):A32.

19 Kharitinov SA,-Yates DH, Barnes PJ. Inhaled glucocorticoids decrease nitric oxide in exhaled air of asthmatic patients. Am $\mathcal{F}$ Resp Crit Care Med 1996;153:454-7.

20 Hamid Q Springall DR, Riveros-Moreno V, et al. Induction of nitric oxide synthase in asthma. Lancet 1993;342:1510-3.

21 Belvisi M, Barnes PJ, Larkin S, et al. Nitric oxide synthase activity is elevated in inflammatory lung disease in humans. Eur $\mathcal{F}$ Pharmacol 1995;283:255-8.

22 Greally P, Hussein MJ, Cook AJ, Sampson AP, Piper PJ, Price JF. Sputum tumour necrosis factor- $\alpha$ and leukotriene concentrations in cystic fibrosis. Arch Dis Child 1993;68: 389-92.

23 Balough K, McCubbins M, Weinberger M, Smits W, Ahrens $R$, Fick $R$. The relationship between infection and inflammation in the early stages of lung disease from cystic fibrosis. Pediatr Pulmonol 1995;20:63-70.

24 Rosenthal M, Bain SH, Cramer D, et al. Lung function in white children aged 4 to 19 years. I. Spirometry. Thorax 1993;48:794-802.

25 Leone AM, Gustafsson LE, Francis PL, Persson MG, Wiklund NP, Moncada S. Nitric oxide is present in exhaled breath in humans: direct GC-MS confirmation. Biochem biophys Res Commun 1994;201:883-7.

26 Grasemann $\mathrm{H}$, Ioannidis I, Wallot $M$, de Groot H, Ratjen F Airway nitric oxide (NO) in cystic fibrosis [abstr]. Am $\dot{f}$ Airway nitric oxide (NO) in cystic
Respir Crit Care Med 1996;153:A70.

27 Warren JB, Loi R, Rendell NB, Taylor GW. Nitric oxide is inactivated by the bacterial pigment pyocyanin. Biochem $\mathscr{f}$ 1990;266:921-3.

28 Lundberg JON, Farkas-Szallasi T, Weitzberg E, et al. High nitric oxide production in human paranasal sinuses. Nature Med 1995;1:370-3.

29 Ramsey B, Richardson MA. Impact of sinusitis in cystic fibrosis. F Allergy Clin Immunol 1992;90:547-52.

30 Lundberg JON, Weitzberg E, Nordvall SL, Kuylenstierna R, Lundberg JM, Alving K. Primarily nasal origin of exhaled nitric oxide and absence in Kartagener's syndrome. Eur Resp $₹$ 1994;7:1501-4. 